\title{
Pharmacogenetics of CYP2B6, CYP2A6 and UGT2B7 in HIV treatment in African populations: focus on efavirenz and nevirapine
}

\author{
Antoinette Čolić ${ }^{1}$, Marco Alessandrini ${ }^{2}$, and Michael S. Pepper ${ }^{2}$ \\ ${ }^{1}$ Department of Biochemistry, Faculty of Natural and Agricultural SciencesSchool of Biological Science, University of Pretoria, Pretoria, South Africa \\ and ${ }^{2}$ Department of Immunology, Faculty of Health Sciences, Institute for Cellular and Molecular Medicine, University of Pretoria, Pretoria, South \\ Africa
}

Keywords

Drug metabolism, hepatotoxicity, HIV/AIDS, inter-ethnic variability, neurotoxicity

\begin{abstract}
The CYP450 and UGT enzymes are involved in phase I and phase II metabolism of the majority of clinically prescribed drugs, including the non-nucleoside reverse transcriptase inhibitors, efavirenz and nevirapine, used in the treatment of HIV/AIDS. Variations in the activity of these enzymes due to gene polymorphisms can affect an individual's drug response or may lead to adverse drug reactions. There is an inter-ethnic distribution in the frequency of these polymorphisms, with African populations exhibiting higher genetic diversity compared to other populations. African specific alleles with clinical relevance have also emerged. Given the high prevalence of HIV/AIDS in subSaharan Africa, understanding the frequency of pharmacogen-etically relevant alleles in populations of African origin, and their impact on efavirenz and nevirapine metabolism, is becoming increasingly critical. This review aims to investigate ethnic variation of CYP2B6, CYP2A6 and UGT2B7, and to understand the pharmacogenetic relevance when comparing frequencies in African populations to other populations worldwide.
\end{abstract}

\section{Introduction}

\section{Drug metabolism and pharmacogenomics}

Pharmacogenomics and pharmacogenetics take into consideration an individual's genotype during drug development and drug prescription, in order to personalize therapy. Commonly, pharmacogenetics refers to how variation in a single gene influences an individual's response to a single drug, while pharmacogenomics refers to how all of the genes in the genome can collectively influence responses to drugs (https:// www.pharmgkb.org/page/faqs [last accessed 27 April 2014]). The overall aim of pharmacogenetics is to improve health care by increasing the number of responders while decreasing the number of adverse drug reactions. Genetic variation is investigated for drug transporters, drug metabolizing enzymes as well as drug targets. This review will focus on drug metabolizing enzymes.

The most important class of the drug metabolizing enzymes is the cytochrome P450 (CYP450) family, which is involved in phase I metabolism of various endogenous and exogenous compounds, including the majority of clinically prescribed drugs (Warnich et al., 2011). CYP450 enzymes are heme oxygenases, found mainly in the liver. They are involved in converting liposoluble compounds into more hydrosoluble

Address for correspondence: Prof. Michael S. Pepper, Department of Immunology, Faculty of Health Sciences, University of Pretoria, P.O. Box 2034, Pretoria 0001, South Africa. Tel: +27 (0)12 319 2190. Fax: +27 (0)12 319 2946. E-mail: michael.pepper@up.ac.za compounds, most commonly through the addition of a hydroxyl or other hydrophilic group, in order for the compound to be effectively eliminated by the kidneys. The major families involved in phase I biotransformation reactions of drugs are CYP1, CYP2 and CYP3.

High nucleotide diversity has been reported for the CYP450 genes. Single nucleotide polymorphisms (SNPs) are defined as a variation in the nucleotide base at a single position in a DNA sequence. When a SNP is present within a gene and occurs in at least $1 \%$ of the population, the different representation of that gene is then known as an allele. Over 400 alleles have been assigned to date across the CYP1, CYP2 and CYP3 subfamilies (http://www.cypalleles.ki.se/ [last accessed 28 Oct 2014]). Polymorphisms in genes encoding the drug metabolizing enzymes may affect the activity of the gene products (Ingelman-Sundberg et al., 2007). The consequence of these variations on enzyme activity and substrate metabolism are shown in Figure 1. SNPs and insertions and deletions of DNA sequences (indels), causing frame shift mutations or premature stop codons, can result in either no functional enzyme being formed, unstable enzymes leading to reduced metabolism or even increased enzyme activity. Certain mutations may also lead to amino acid changes that change substrate specificity. Copy number variation, such as multiple copies of a functional allele, can lead to higher enzyme levels and increased metabolism.

It is therefore evident that these polymorphisms may lead to wide variations in catalytic activities (Alessandrini et al., 2013). Individuals can be classified into four phenotypic 


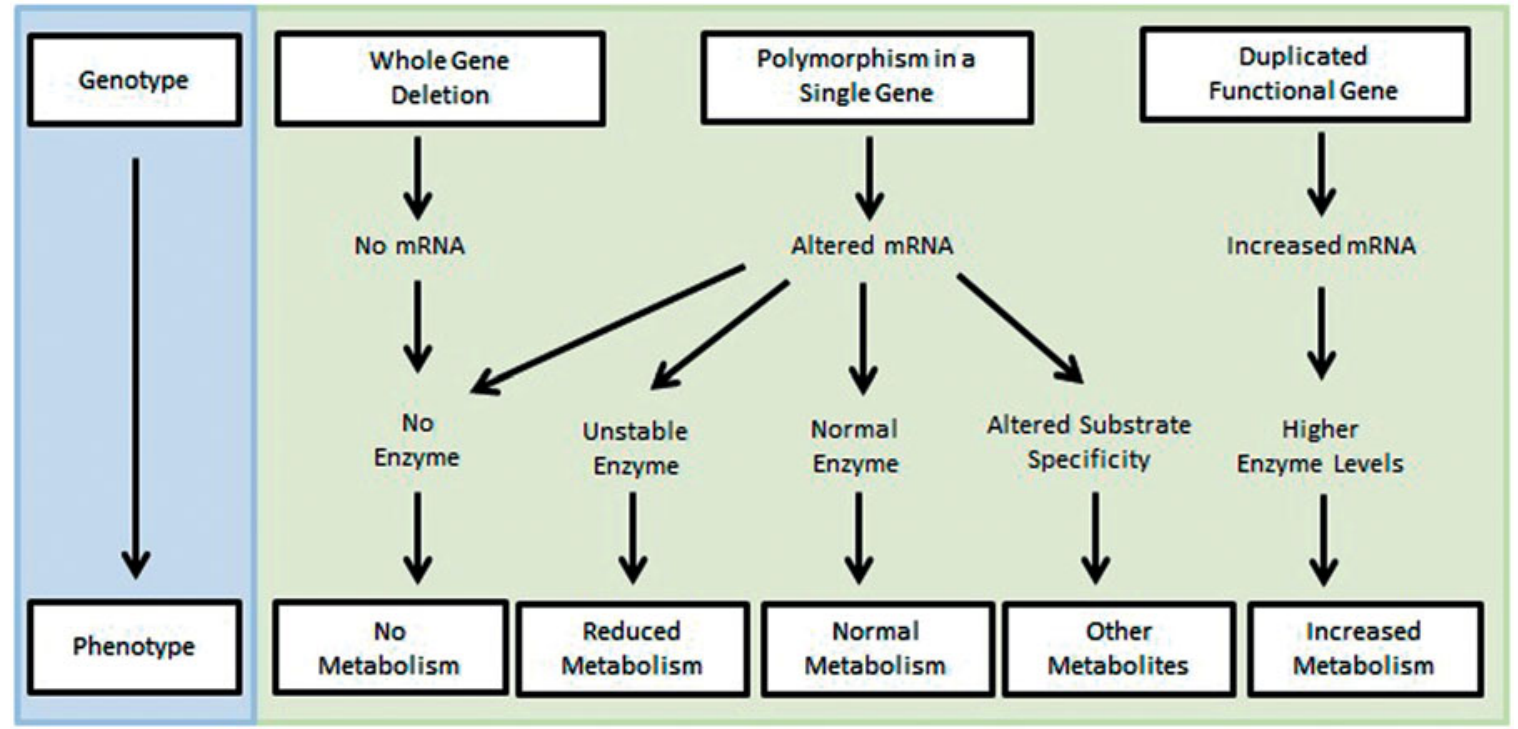

Figure 1. Consequences of mutations in the CYP genes. Variations in genes encoding for the CYP450 enzymes result in altered mRNA expression leading to a change in enzyme activity and metabolism. Adapted with permission from Ingelman-Sundberg (2007) and Henry Stewart Talks.

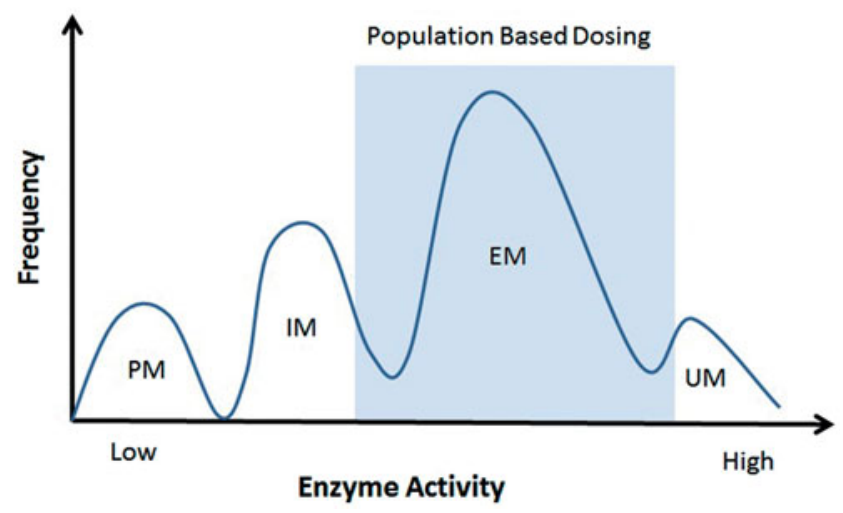

Figure 2. Frequency of phenotypes based on CYP450 mutations. Population based dosing results in standard dosing levels being representative of the level required by EM individuals. The PM and UM groups are most affected, either receiving a higher or lower dosage than required, leading to toxicity or absence of drug response, respectively. Adapted with permission from Ingelman-Sundberg (2007) and Henry Stewart Talks.

groups: ultrarapid metabolizers (UM), generally with more than two active genes, or SNPs that result in induced expression and increased activity; extensive metabolizers (EM), carrying two functional genes; intermediate metabolizers (IM), characterized by genetic variants that result in reduced enzymatic activity; and poor metabolizers (PM), who lack functional enzymes due to defective or deleted genes (Ingelman-Sundberg et al., 2007). Figure 2 shows the general frequency of each phenotype across the population, with the majority of the population falling into the EM group. Population-based dosing results in the standard dosing levels for a given drug being set at a level considered to be appropriate for the majority of the population, despite the differences in phenotype present. Population-based dosing therefore results in PM individuals having higher plasma concentrations of drugs than necessary leading to adverse drug reactions and toxicity. In contrast, the absence of a drug response may be seen in UM individuals. The opposite is true for pro-drugs which need to be activated in order to exert their biological activity.

Another important family of drug metabolizing enzymes is the uridine-diphosphate-glucuronosyltransferases (UGT) involved in phase II drug metabolism. The UGT enzymes are involved in conjugating a glucuronic acid group to the functional group of a specific substrate (Guillemette, 2003), resulting in a more hydrophilic and therefore more easily excretable molecule. The UGT enzymes are also known to be polymorphic, with certain variants having pharmacogenetic relevance (Guillemette, 2003). Similar to the CYP450 enzymes, genetic variations can be in the form of SNPs, indels and multiple copies of functional and non-functional alleles, and can occur in the regulatory and coding sequences, introns and the $5^{\prime}$ - and $3^{\prime}$-untranslated regions. These variations can significantly alter the glucuronidation capacity of the individual carrying a variant, resulting in either ineffective drug levels due to rapid metabolism, or toxicity due to slow metabolism (Court, 2010). The UGT enzymes include more than 26 genes, 18 of which code for functional proteins. They are grouped into two families, UGT1 and UGT2, which are further subdivided into subfamilies UGT1A, UGT2A and UGT2B. Inter-individual variation in the UGT enzymes has also been observed, with UGT1A showing the highest and UGT2B7 the lowest variability (Court, 2010).

\section{Pharmacogenetics in Africa}

The majority of pharmacogenetic studies to date have been performed on Caucasian and Asian populations. Pharmacogenetic profiles based on these studies are then extrapolated for use in other populations, despite the fact that variant frequencies can differ markedly between different populations (Ikediobi et al., 2011). Dandara et al. (2014) provide a review on the importance of CYP450 pharmacogenetics in African populations and the implications for public health. The authors highlight that a large number of ethnic groups need to be characterized to capture the full 
extent of existing genetic diversity. Moreover, by excluding African populations from drug research, unexpected adverse drug reactions may occur when these populations, which have novel variations, are exposed to drugs for the first time.

Polymorphisms exhibit inter-individual as well as interpopulation differences. When investigating genetic variation within and between population groups for the CYP2B6 and UGT2B7 genes, $\pm 90 \%$ of the genetic variation was observed among individuals within a population, i.e. due to interindividual differences. The remaining $10 \%$ of genetic variation occurs between different populations or ancestral groups, i.e. inter-population differences ( $\mathrm{Li}$ et al., 2012). $\mathrm{Li}$ et al. (2012) also compared the extent of genetic diversity in the CYP2B6 and UGT2B7 enzymes across a variety of ancestral backgrounds and concluded that genetic variation among individuals within the same population is greater for UGT2B7 than for the highly polymorphic CYP2B6 enzyme. However, genetic diversity among individuals in different population groups is higher for CYP2B6 than UGT2B7. These findings indicate that the impact of ancestry on genetic diversity may be greater for CYP2B6 than for UGT2B7. A clear example of this inter-population difference can be seen in a study investigating the extent of $C Y P 2 B 6$ genetic variability in populations of African and Asian origin. The study found a large number of polymorphisms and a low frequency of the $C Y P 2 B 6^{*} 1$ wild-type allele in only 44.3 and $39 \%$ of African-Americans and Ghanaians, respectively, compared to the significantly lower number of polymorphisms and higher frequency of the *1 wild-type allele in 68 and $76.1 \%$ of Japanese and Koreans, respectively (Klein et al., 2005). It was concluded that Africans exhibit a higher degree of genetic variation than Asian populations with respect to this gene.

Intra-ethnic genetic diversity within Africa has also been reported. The Bantu-speaking populations of Africa make up the majority of sub-Saharan African people. They originated from the Niger-Congo regions, and expanded throughout eastern and southern parts of Africa. The older Khoisan populations based in the South-Western parts of Africa make up the remaining African population. In South Africa, there is also a Cape mixed ancestry population, which originated from the sub-Saharan African Bantu-speakers, with influences from both Europe and Asia (de Wit et al., 2010). When two Bantu-speaking populations from Cameroon and South Africa were compared, they were found to be genetically similar with regard to CYP2A6 and CYP2B6. However, there were some statistically significant differences between the genotype frequencies seen in the two populations with respect to CYP1A2, CYP3A4 and CYP3A5 (Swart et al., 2012). The difference in genotype frequencies demonstrates that African populations show intra-ethnic genetic diversity that needs to be characterized appropriately, and that even linguistically related Bantu-speaking populations may not be genetically homogenous. Allele frequencies between these two Bantu-speaking populations were compared to other populations, including other African, Asian and Caucasian populations. In general, significant differences were seen in allele frequencies between individuals of African origin compared to Asian and Caucasian populations, but statistically significant differences were also reported between the
South African population and another Bantu-speaking population from Yoruba in Nigeria with respect to CYP2A6. It is therefore evident that it is important to conduct pharmacogenetic studies across a wide range of ethnic backgrounds on different continents. Unfortunately, there have been limited reports detailing pharmacogenetically relevant genes in Africa, even though African populations show higher levels of genetic diversity compared to other populations (Tishkoff et al., 2009).

Recent reports also suggest that the existence of population specific alleles that may be clinically relevant. The CYP $2 B 6 * 18$ allele, characterized by the $983 \mathrm{~T}>\mathrm{C}$ SNP which results in decreased protein expression (Wang et al., 2006), is thought to be an African specific allele. Only individuals of African ancestry and not those of Asian or European ancestry have been reported to carry the allele (Li et al., 2012; Mehlotra et al., 2007). In a study by Radloff et al. (2013), eight novel functionally uncharacterized nonsynonymous variants were found in the CYP2B6 gene in a Rwandese population, and it was demonstrated that four of these variants resulted in complete or almost complete loss of function. Three novel SNPs in the CYP2B6 gene were found in a Zimbabwean population $(341 \mathrm{~T}>\mathrm{C}, 444 \mathrm{G}>\mathrm{T}$ and $1158 \mathrm{~A}>\mathrm{G}$ ), and two novel SNPs in a Ugandan population $(856 \mathrm{C}>\mathrm{T}$ and $1459 \mathrm{C}>\mathrm{A}$; Jamshidi et al., 2010). These findings demonstrate the potentially large number of African specific alleles that might exist.

Discordance between genotype and phenotype exists in certain African populations, and has been well documented for the CYP450 enzymes (Alessandrini et al., 2013). For example, African individuals that appear to have wild-type genotypes have been reported to show a PM phenotype. This discordance may be due to a lack of comprehensive genotyping or as a result of population specific alleles that have not yet been identified. Most of the research that has been done to date on pharmacogenetically relevant genes has focused on a subset of well-known and well-described SNPs. As a result, individuals who do not carry at least one of the SNPs from this subset are characterized as having a wild-type genotype. However, the previously mentioned studies demonstrate the need to explore potentially novel variants that may be functionally relevant, particularly in poorly investigated African populations and may help to explain genotypephenotype correlations more clearly. All possible variants in the complete gene(s) of interest should therefore be sought using next generation sequencing as opposed to genotyping for specific SNPs. In silico analyses will then allow for the determination of possible functional implications of novel variations, and thereby identify variants that may be functionally relevant and require additional in vitro and/or in vivo investigations.

Africa is severely affected by both communicable and noncommunicable diseases. Although the continent accounts for only $15.5 \%$ of the global population, it carries approximately $25 \%$ of the global disease burden (Murray et al., 2013). Adverse drug reactions further complicate the situation due to resulting non-compliance, adding to morbidity, mortality and increasing medical costs across the continent. Pharmacogenetic studies can therefore add value by helping to understand the degree of genetic variability on the 
continent, as well as by defining populations that may be at a higher risk for developing either toxicity or a reduced response to certain drugs, with the goal of improved healthcare in Africa (Alessandrini \& Pepper, 2014).

When assessing the number of African countries for which frequency data of clinically relevant CYP450 alleles has been reported, it is clear that there is a lack of data, with several regions for which no pharmacogenetic data exists. A discrepancy between the disease burden in a specific region and the pharmacogenetically relevant genes studied in relation to those diseases is also apparent (Alessandrini \& Pepper, 2014). Alessandrini \& Pepper (2014) define priority pharmacogenetics as the CYP450 genes that should be investigated as a priority given both the disease burden and the extent of CYP450 data currently available in a given region. In southern Africa, HIV/AIDS and malaria rank as the top two diseases contributing to the health burden; however, the majority of CYP450 data that is available for this region relates to genes encoding enzymes that metabolize drugs required for the treatment of cardiovascular/circulatory disease, diabetes and major depressive disorders. The discordance between the health burden and available CYP450 reports clearly points to the fact that the genes associated with the metabolism of drugs used in the treatment of HIV/ AIDS should be studied as a top priority in the southern Africa region.

\section{Role of pharmacogenetics in HIV therapy}

In Africa, HIV/AIDS constitutes a major disease burden, with sub-Saharan Africa being more affected than any other region in the world (Joint United Nations Programme on HIV/AIDS, 2011). Highly active antiretroviral therapy (HAART) is widely used in the treatment of HIV/AIDS; however treatment is compromised by the development of drug resistance, a high degree of variability in drug response and high rates of adverse drug reactions. While there are many factors which may influence a person's response to HAART, genetic polymorphisms affecting the activity of key drug metabolizing enzymes is likely to be an important source of inter-patient variability. The CYP450 and UGT enzymes play a major role in phase I and phase II metabolism of drugs, respectively, and thus polymorphisms in the CYP450 and/or UGT genes can result in inter-patient variability in antiretroviral drug efficacy and toxicity. In a study by Kwara et al. (2009b), it was concluded that pharmacogenomic testing used for the estimation of the appropriate dose of the antiretroviral drug efavirenz, should incorporate both oxidative (CYP450) as well as glucuronidation (UGT) pathways.

\section{Pharmacogenetics and HIV therapy}

\section{Treatment of HIV}

Antiretroviral drugs target various elements of the HIV replication cycle, and include nucleoside/nucleotide reverse transcriptase inhibitors (NRTI), non-nucleoside reverse transcriptase inhibitors (NNRTI), protease inhibitors (PI) and entry inhibitors. Standard antiretroviral treatment usually includes a combination of drugs targeting these different elements to effectively control HIV infection and reduce resistance. Combinations usually include two NRTIs as well as one NNRTI or PI (Department of Health (DOH), Republic of South Africa, 2013). The CYP450 enzymes do not play a central role in the metabolism of NRTIs, for which hepatic glucoronidation is believed to be the predominant metabolic pathway (Mahungu et al., 2009). The CYP450 enzymes are however involved in the metabolism of NNRTI's, including efavirenz and nevirapine, protease inhibitors, the CCR5 coreceptor antagonist maraviroc and the intergrase inhibitor elvitegravir (Michaud et al., 2012).

Efavirenz is included in first line antiretroviral regimens for all adults and adolescents in South Africa, and is also included in the treatment of patients co-infected with tuberculosis (TB) [Department of Health (DOH), Repulic of South Africa, 2013]. Efavirenz blocks viral replication by binding to reverse transcriptase thereby altering the function of the enzyme and rendering it incapable of converting viral RNA to DNA (Ward et al., 2003). Both the CYP450 as well as UGT enzymes play a role in the metabolism of efavirenz (Figure 3). Efavirenz is mainly metabolized by CYP2B6 into 8-hydroxyefavirenz and to a lesser extent by CYP2A6 into 7-hydroxyefavirenz, with CYP3A4/5 and CYP1A2 playing a minor role in this step (Ward et al., 2003; Whirl-Carrillo et al., 2012). N-Glucuronide-efavirenz is formed when efavirenz undergoes conjugation by UGT2B7 (Bélanger et al., 2009). It has been proposed however that CYP2A6 and UGT2B7 only play a significant role in the efavirenz pathway when CYP2B6 is impaired (di Iulio et al., 2009). Significant inter-individual variability in efavirenz plasma concentrations has been reported, with increased plasma levels leading to adverse side effects including neurotoxicity.
Figure 3. Primary efavirenz metabolism by CYP450 and UGT enzymes. Efavirenz is mainly metabolized by CYP2B6 into 8hydroxyefavirenz, with CYP2A6, CYP3A4/5 and CYP1A2 playing a minor role in this step. EFV can also be hydroxylated to 7hydroxyefavirenz by CYP2A6, although efavirenz 8-hydroxylation is the major route of clearance. $\mathrm{N}$-glucuronide-efavirenz is formed when efavirenz undergoes conjugation by UGT2B7. Copyright to PharmGKB. Adapted with permission from PharmGKB and Stanford University (Whirl-Carrillo et al., 2012). Original pathway can be found at http://www.pharmgkb.org/pathway/ PA166123135.

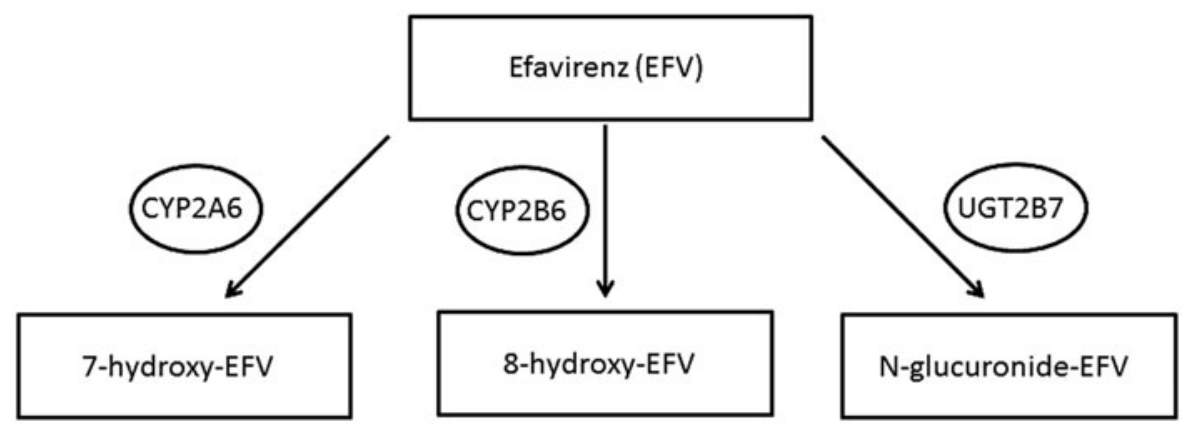


Figure 4. Primary and secondary nevirapine metabolism by CYP450 and UGT enzymes. Nevirapine is metabolized by CYP2B6 into 3- and 8-hydroxynevirapine, and CYP3A4 into 2- and 12-hydroxynevirapine. CYP3A5, CYP2C9 and CYP2D6 play a minor role in these steps. Nevirapine also undergoes glucuronide conjugation of the hydroxyl metabolites by the UGT enzymes. Copyright to PharmGKB. Adapted with permission from PharmGKB and Stanford University (WhirlCarrillo et al., 2012). Original pathway can be found at http://www.pharmgkb.org/pathway/PA165950411.

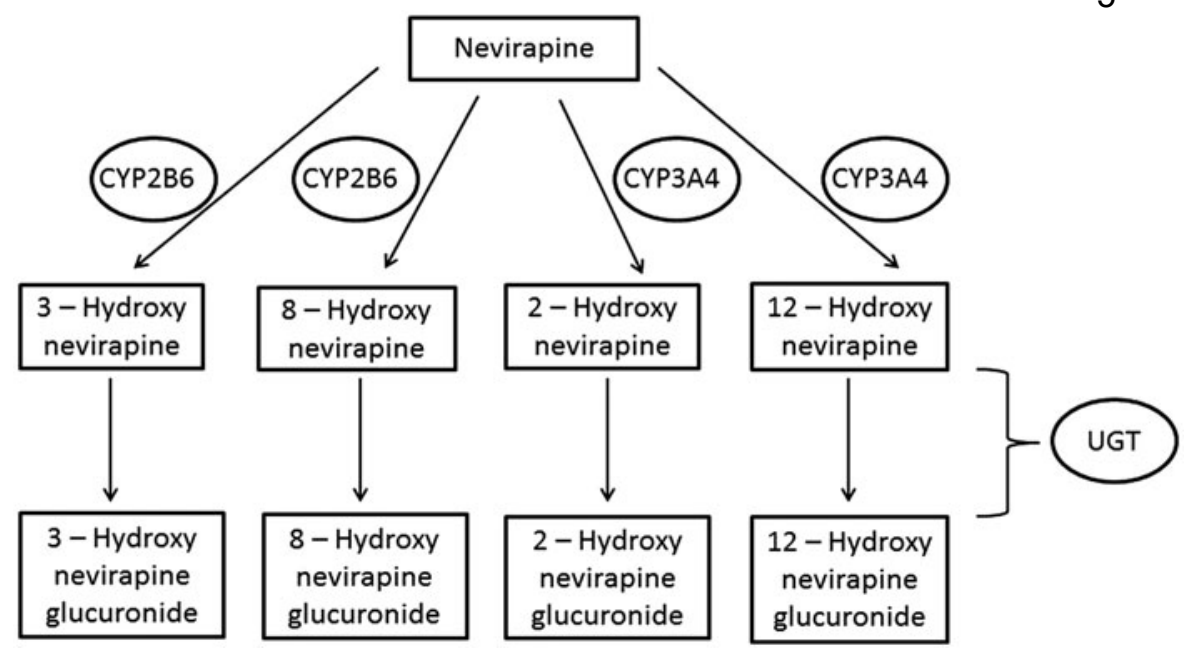

In cases where persistent neurotoxicity is seen, nevirapine or a protease inhibitor is substituted. In South Africa, nevirapine is also the preferred treatment for infants of HIV infected women to prevent mother to child transmission (Department of Health (DOH) Repulic of South Africa, 2013). Nevirapine is also still extensively used in other African regions due to its efficacy and affordability (Ciccacci et al., 2010). Decreased metabolism of nevirapine results in increased plasma levels leading to adverse side effects including hepatotoxicity (Haas et al., 2006). Nevirapine is mainly metabolized by CYP2B6 into 3- and 8-hydroxynevirapine and CYP3A4 into 2- and 12-hydroxynevirapine. Nevirapine also undergoes glucuronide conjugation of the hydroxyl metabolites by the UGT enzymes (Riska et al., 1999; Whirl-Carrillo et al., 2012; Figure 4).

Drug-drug interactions may also be a source of variation that can contribute to inter-individual responses as well as adverse drug reactions. This is particularly important in the present context as antiretroviral therapy constitutes a combination of drugs as previously described. Given the high incidence of TB infection in HIV-positive individuals, drugdrug interactions between anti-TB drugs such as rifampicin and antiretroviral drugs such as efavirenz should also be considered, particularly since rifampicin is known to induce CYP2B6 activity.

The review by Dandara et al. (2014) provides a summary of efavirenz metabolism and CYP2B6 pharmacogenetics in African populations, specifically the effect of the CYP2B6 $516 \mathrm{G}>\mathrm{T}$ variant. However, other CYP2B6 polymorphisms may also play a role in altered enzyme activity, as may polymorphisms in CYP2A6 and UGT2B7. Frequencies of all reported polymorphisms in the CYP2A6, CYP2B6 and UGT2B7 genes associated with altered efavirenz and nevirapine plasma concentrations have therefore been reviewed.

\section{CYP2B6, CYP2A6 and UGT2B7}

\section{CYP2B6}

The CYP2B6 subfamily of enzymes is known to be highly polymorphic, with 38 allelic variants reported to date (http://www.cypalleles.ki.se/cyp2b6.htm [last accessed
28 October 2014]). Various polymorphisms have been shown to be clinically relevant resulting in increased or decreased metabolism of target drugs. Table 1 provides a summary of the frequency of variants in the CYP2B6 gene in African populations, and the resulting effect on efavirenz and nevirapine metabolism.

\section{$C Y P 2 B 6^{*} 6(516 G>T$ and $785 A>G)$}

Allele frequencies in African populations. The $C Y P 2 B 6^{*} 6$ haplotype is characterized by the presence of two nonsynonymous variants $516 \mathrm{G}>\mathrm{T}$ and $785 \mathrm{~A}>\mathrm{G}$ (Thorn et al., 2010). Strong linkage disequilibrium between $516 \mathrm{G}>\mathrm{T}$ and $785 \mathrm{~A}>\mathrm{G}$ can be seen in many populations, including Africans, Caucasians, Asians and Hispanics (Li et al., 2012; Maimbo et al., 2012; Mehlotra et al., 2007; Swart et al., 2012, 2013). Substantial inter-population differences in the frequency of the $516 \mathrm{G}>\mathrm{T}$ and $785 \mathrm{~A}>\mathrm{G}$ SNPs have been reported, with higher frequencies seen in African populations. The frequency of the 516G $>\mathrm{T}$ SNP differs significantly between African-Americans and European-Americans (38 and $21.9 \%$, respectively, $p=0.005$ ). Furthermore, $20 \%$ of African-Americans have been shown to be homozygous for the $516 \mathrm{G}>\mathrm{T}$ polymorphism, compared to only $3.4 \%$ of European-Americans (Haas et al., 2004). In other studies, the *6 allele was found to be present in 33-35\% of AfricanAmericans (Klein et al., 2005; Mehlotra et al., 2007).

The *6 haplotype has been reported at high frequencies in Africa. Mehlotra et al. (2007) reported a frequency of $41.5 \%$ in a West African population including Ghana, Guinea, Ivory Coast, Sierra Leone and Senegal. Klein et al. (2005) also reported a high frequency of the $* 6$ haplotype in Ghanaians (46.9\%), and Sarfo et al. (2014) reported a frequency of $48 \%$ for the 516G $>\mathrm{T}$ SNP in another Ghanaian population. In an analysis of the 1000 genomes database, the $516 \mathrm{G}>\mathrm{T}$ and $785 \mathrm{~A}>\mathrm{G}$ SNPs were found in $35-38 \%$ and $22-35 \%$ of populations of African ancestry, respectively, including Luhya (Kenya), Yoruba (Nigeria) and those of African ancestry in the southwestern USA ( $\mathrm{Li}$ et al., 2012). The $516 \mathrm{G}>\mathrm{T}$ variant was observed at a frequency of $20-32 \%$ in a Xhosa population, and at $23-30 \%$ in a Cape mixed ancestry population from South Africa (Ikediobi et al., 2011; 
Table 1. Frequency of CYP2B6 variants and associated phenotype in populations of African origin.

\begin{tabular}{|c|c|c|c|c|c|c|c|c|c|}
\hline \multirow[b]{2}{*}{ Population } & \multicolumn{2}{|c|}{$516 \mathrm{G}>\mathrm{T}$} & \multicolumn{2}{|r|}{$785 \mathrm{~A}>\mathrm{G}$} & \multicolumn{2}{|r|}{$983 \mathrm{~T}>\mathrm{C}$} & \multicolumn{2}{|c|}{$1459 \mathrm{C}>\mathrm{T}$} & \multirow[b]{2}{*}{ References } \\
\hline & Frequency & Phenotype & Frequency & Phenotype & Frequency & Phenotype & Frequency & Phenotype & \\
\hline \multicolumn{10}{|l|}{ South Africa } \\
\hline Xhosa & $20-32 \%(6.25 \%)$ & \multirow{2}{*}{$\begin{array}{l}\text { No significant associ- } \\
\text { ation with changes in } \\
\text { CD4-cell count }\end{array}$} & $32 \%$ & \multirow{2}{*}{$\begin{array}{l}\text { No significant } \\
\text { association with } \\
\text { changes in } \\
\text { CD4-cell count }\end{array}$} & $17 \%$ & - & - & - & \multirow{2}{*}{$\begin{array}{l}\text { Ikediobi et al. } \\
\quad(2011) \text {, } \\
\text { Parathyras et al. } \\
\quad(2009)\end{array}$} \\
\hline $\begin{array}{l}\text { Cape Mixed } \\
\text { Ancestry }\end{array}$ & $23-30 \%(5.71 \%)$ & & $31 \%$ & & $9 \%$ & - & - & - & \\
\hline Bantu & $36 \%(12.5-18.6 \%)^{\mathrm{a}}$ & $\begin{array}{l}\text { Increased efavirenz } \\
\text { plasma concentration }\end{array}$ & - & - & $\begin{array}{l}5.1-12.7 \% \\
(1.7 \%)\end{array}$ & $\begin{array}{l}\text { Increased efavirenz } \\
\text { plasma concentration }\end{array}$ & $1.4-3.1 \%$ & - & Swart et al. (2013) \\
\hline Black & $43 \%(23 \%)$ & $\begin{array}{l}\text { Increased efavirenz } \\
\text { plasma concentra- } \\
\text { tion. Adverse side } \\
\text { effects. No associ- } \\
\text { ation with immune } \\
\text { response (CD4 } \\
\text { count) }\end{array}$ & - & - & - & - & - & - & $\begin{array}{l}\text { Gounden et al. } \\
\text { (2010) }\end{array}$ \\
\hline \multicolumn{10}{|l|}{ Other African } \\
\hline West Africa ${ }^{c}$ & $41.5 \%^{\mathrm{a}}$ & - & - & - & $4.7 \%$ & - & - & - & $\begin{array}{l}\text { Mehlotra et al. } \\
\text { (2007) }\end{array}$ \\
\hline \multirow[t]{2}{*}{ Ghana } & $48.8 \%$ & - & $47.5 \%$ & - & $6.6 \%$ & - & - & - & $\begin{array}{l}\text { Klein et al. } \\
\text { (2005) }\end{array}$ \\
\hline & $48 \%$ & $\begin{array}{l}\text { Increased efavirenz } \\
\text { plasma concentration }\end{array}$ & - & - & $4 \%$ & $\begin{array}{l}\text { Increased efavirenz } \\
\text { plasma concentration }\end{array}$ & - & - & $\begin{array}{l}\text { Sarfo et al. } \\
\quad(2014)\end{array}$ \\
\hline Mozambique & $41-49 \%(17-23 \%)$ & $\begin{array}{l}\text { No association with } \\
\text { nevirapine-induced } \\
\text { hepatotoxicity }\end{array}$ & $\begin{array}{c}43-45 \% \\
(20 \%)\end{array}$ & - & $5-7 \%$ & $\begin{array}{l}\text { Association with nevir- } \\
\text { apine-induced } \\
\text { hepatotoxicity }\end{array}$ & - & - & $\begin{array}{l}\text { Ciccacci et al. } \\
\text { (2010) }\end{array}$ \\
\hline Botswana & $36.6 \%(17.8 \%)^{\mathrm{a}}$ & - & - & - & - & - & - & - & $\begin{array}{l}\text { Gross et al. } \\
\quad(2008)\end{array}$ \\
\hline Malawi & $31 \%$ & $\begin{array}{l}\text { Increased nevirapine } \\
\text { exposure }\end{array}$ & & & & & & & $\begin{array}{l}\text { Brown et al. } \\
\quad(2012)\end{array}$ \\
\hline \multirow[t]{2}{*}{ Zimbabwe } & $48-49 \%^{\mathrm{a}}$ & $\begin{array}{l}\text { Increased efavirenz } \\
\text { plasma concentration }\end{array}$ & - & - & & $\begin{array}{l}\text { Increased efavirenz } \\
\text { plasma concentration }\end{array}$ & - & - & $\begin{array}{l}\text { Jamshidi et al. } \\
\text { (2010), } \\
\text { Nyakutira et al. } \\
(2008)\end{array}$ \\
\hline & $42 \%$ & $\begin{array}{l}\text { Significantly associated } \\
\text { with efavirenz } \\
\text { plasma concentration }\end{array}$ & $42 \%$ & - & $9 \%$ & $\begin{array}{l}\text { Heterozygous patients } \\
\text { had a fourfold higher } \\
\text { efavirenz plasma } \\
\text { concentration }\end{array}$ & - & - & $\begin{array}{l}\text { Maimbo et al. } \\
\text { (2012) }\end{array}$ \\
\hline Uganda & $29-35.6 \%$ & $\begin{array}{l}\text { Increased efavirenz } \\
\text { plasma } \\
\text { concentration. Incr- } \\
\text { eased nevirapine } \\
\text { concentration }\end{array}$ & $32-36.4 \%$ & - & $5.4-10.4 \%$ & $\begin{array}{l}\text { Increased efavirenz } \\
\text { plasma concentration }\end{array}$ & - & - & $\begin{array}{l}\text { Jamshidi et al. } \\
\text { (2010), } \\
\text { Penzak et al. } \\
\text { (2007), } \\
\text { Mukonzo et al. } \\
\text { (2009) }\end{array}$ \\
\hline
\end{tabular}




\begin{tabular}{|c|c|c|c|c|c|c|c|c|c|}
\hline Tanzanian & $41.8 \%(18.6 \%)$ & $\begin{array}{l}\text { Significant predictor of } \\
\text { plasma and intracel- } \\
\text { lular efavirenz } \\
\text { concentration }\end{array}$ & - & - & $6.9 \%^{\mathrm{b}}$ & - & - & - & $\begin{array}{l}\text { Ngaimisi et al. } \\
\text { (2013), } \\
\text { Wang et al. } \\
\text { (2006) }\end{array}$ \\
\hline Ethiopia & $31.4 \%(8.7 \%)$ & $\begin{array}{l}\text { Significant predictor of } \\
\text { plasma and intracel- } \\
\text { lular efavirenz } \\
\text { concentration }\end{array}$ & - & - & - & - & - & - & $\underset{(2013)}{\text { Ngaimisi et al. }}$ \\
\hline Cameroon & $37 \%$ & - & $22.50 \%$ & - & - & - & $1 \%$ & - & $\begin{array}{l}\text { Swart et al. } \\
\text { (2012) }\end{array}$ \\
\hline \multicolumn{10}{|l|}{$\begin{array}{l}1000 \text { Genomes and } \\
\text { HapMap }\end{array}$} \\
\hline $\begin{array}{l}1000 \text { genomes } \\
\text { African } \\
\text { ancestry }^{\mathrm{d}}\end{array}$ & $35-38 \%$ & - & $22-35 \%$ & - & $4-12 \%$ & - & - & - & $\begin{array}{l}\text { Li et al. } \\
\quad(2012)\end{array}$ \\
\hline $\begin{array}{c}\text { Yoruba } \\
\text { (Nigeria) } \\
\text { HapMap }\end{array}$ & $45 \%$ & - & - & - & $4 \%$ & - & - & - & $\begin{array}{l}\text { Ikediobi et al. } \\
\text { (2011) }\end{array}$ \\
\hline $\begin{array}{l}\text { Luyha (Kenya) } \\
\text { HapMap }\end{array}$ & $31 \%$ & - & - & - & $7 \%$ & - & - & - & $\begin{array}{l}\text { Ikediobi et al. } \\
\text { (2011) }\end{array}$ \\
\hline $\begin{array}{l}\text { Maasai } \\
\text { (Kenya) } \\
\text { HapMap }\end{array}$ & $37 \%$ & - & - & - & $2 \%$ & - & - & - & $\begin{array}{l}\text { Ikediobi et al. } \\
\text { (2011) }\end{array}$ \\
\hline \multirow[t]{2}{*}{$\begin{array}{l}\text { African-American } \\
\text { African- } \\
\text { American }\end{array}$} & $38 \%(20 \%)$ & $\begin{array}{l}\text { Efavirenz plasma con- } \\
\text { centration three times } \\
\text { higher for 516TT } \\
\text { genotype. Central } \\
\text { nervous system side } \\
\text { effects after one } \\
\text { week }\end{array}$ & - & - & - & - & $1 \%$ & $\begin{array}{l}\text { No association } \\
\text { with efavirenz } \\
\text { central nervous } \\
\text { system side effects }\end{array}$ & $\begin{array}{l}\text { Haas et al. } \\
\quad \text { (2004) } \\
\text { s }\end{array}$ \\
\hline & $33-35 \%^{\mathrm{a}}$ & & $29.80 \%$ & - & $4.4-7.5 \%$ & - & - & - & $\begin{array}{l}\text { Mehlotra et al. } \\
\text { (2007), } \\
\text { Klein et al. } \\
\text { (2005) }\end{array}$ \\
\hline
\end{tabular}

Percentages in brackets indicate homozygous individuals. "_," no data present in the published study.

${ }^{\text {a }}$ Frequency relates to the $* 6$ haplotype.

${ }^{\mathrm{b}}$ Frequency relates to the $* 16$ haplotype

${ }^{c}$ West African populations include Ghana, Guinea, Ivory Coast, Sierra Leone and Senegal.
${ }^{\mathrm{d}} 1000$ genomes African Ancestry populations include Luhya (Kenya), Yoruba (Nigeria) and African ancestry from southwest USA. 
Parathyras et al., 2009). A total of $6.25 \%$ of individuals in the Xhosa population were found to be homozygous for the $516 \mathrm{G}>\mathrm{T}$ SNP, as were $5.71 \%$ of the Cape mixed ancestry population (Parathyras et al., 2009). The $516 \mathrm{G}>\mathrm{T}$ variant was reported at a frequency of 45,31 and $37 \%$ in the Yoruba (Nigeria), Luhya (Kenya) and Maasai (Kenya) HapMap populations, respectively (Ikediobi et al., 2011). Within a Bantu-speaking South African population, the $C Y P 2 B 6^{*} 6$ allele was found in $36 \%$ of individuals, amongst whom $18.6 \%$ of HIV/AIDS patients and $12.5 \%$ of HIV-negative individuals were found to be homozygous for this allele (Swart et al., 2013). In another HIV-positive South African population, the allele frequency of the $516 \mathrm{G}>\mathrm{T}$ SNP was $43 \%$, with $23 \%$ being homozygous and $41 \%$ heterozygous (Gounden et al., 2010). In a population from Mozambique, the $516 \mathrm{G}>\mathrm{T}$ SNP was found in $41-49 \%$ of individuals, with $17-23 \%$ of individuals being homozygous (Ciccacci et al., 2010). The $785 \mathrm{~A}>\mathrm{G}$ SNP was found in $43-45 \%$ of these individuals, with $20 \%$ having a homozygous genotype. The CYP2B $6^{*} 6$ haplotype is also common in Botswana. In a study involving $101 \mathrm{HIV}$-positive Batswana, the $C Y P 2 B 6^{*} 6$ allele was present in $36.6 \%$ individuals, and the homozygous haplotype was present in $17.8 \%$ of individuals (Gross et al., 2008). A high allele frequency of $49 \%$ for the $* 6$ allele was seen in HIV patients in Zimbabwe (Nyakutira et al., 2008). The $C Y P 2 B 6^{*} 6$ allele frequency also differed significantly between a Zimbabwean and a Ugandan population, being 48 and $17 \%(p<0.004)$, respectively (Jamshidi et al., 2010). In another Ugandan population, the $516 \mathrm{G}>\mathrm{T}$ and $785 \mathrm{~A}>\mathrm{G}$ SNPs were found in 35.6 and $36.4 \%$ of the population, respectively (Mukonzo et al., 2009). Ngaimisi et al. (2013) found the frequency of the $516 \mathrm{G}>\mathrm{T}$ SNP to be significantly higher in Tanzanians (41.8\%) than Ethiopians (31.4\%), with $18.6 \%$ compared to only $8.7 \%$ homozygous individuals in the Tanzanian and Ethiopian populations, respectively.

Effect of variants on efavirenz and nevirapine plasma concentration. The CYP $2 B 6^{*} 6$ haplotype is associated with decreased enzyme activity, with the $516 \mathrm{G}>\mathrm{T}$ SNP being largely responsible. Individuals with either a $* 1 / * 6$ or $* 6 / * 6$ haplotype have significantly decreased CYP2B6 protein expression, and a decrease in efavirenz metabolism (Desta et al., 2007). Individuals within an adult AIDS clinical trials group with a 516TT genotype had a three-fold higher efavirenz plasma exposure (defined as the 24-h area under the curve) than individuals with the 516GG wild-type genotype (Haas et al., 2004). Efavirenz plasma clearance in this same group was 23 and $54 \%$ lower in individuals with the 516GT and 516TT genotype respectively when compared to the wild-type $516 \mathrm{GG}$ genotype. The $516 \mathrm{G}>\mathrm{T}$ genotype was also associated with central nervous system side effects after 1 week of efavirenz medication, although central nervous system side effects were not significant in later weeks. Elens et al. (2010) found a clear linear relationship between efavirenz plasma concentrations and the number of $516 \mathrm{G}>\mathrm{T}$ mutated alleles. The 516TT genotype was significantly associated with increased efavirenz plasma concentrations in a Ghanaian population, with the 516G $>\mathrm{T}$ SNP accounting for as much as $45 \%$ of the variability using a linear regression analysis
(Kwara et al., 2009b). Patients with the homozygous 516TT genotype in an HIV-positive South African population had significantly higher efavirenz concentrations than those with the GG or GT genotype, with 516TT patients experiencing more severe adverse side effects (Gounden et al., 2010). The CYP2B6*6 allele was found to be a significant predictor of both plasma and intracellular efavirenz concentrations in both Tanzanian and Ethiopian populations (Ngaimisi et al., 2013). An increase in efavirenz concentration is associated with an increase in the number of loss of function alleles, namely, CYP $2 B 6 * 6$, $* 18, * 20$ and $* 27$, in both Zimbabwean and Ugandan populations, with the number of either the $516 \mathrm{G}>\mathrm{T}$ or 983T $>C$ alleles having the greatest impact on increasing efavirenz concentrations (Jamshidi et al., 2010). Mukonzo et al. (2009) reported a $21 \%$ lower oral clearance of efavirenz in another Ugandan population for individuals homozygous for the *6 allele.

In a Bantu-speaking South African HIV-positive population, 35\% had plasma efavirenz levels above the therapeutic range of $4 \mu \mathrm{g} / \mathrm{ml}$, which is likely to be associated with toxicity (Swart et al., 2013). Ninety-two percent of these patients with high plasma efavirenz levels were carriers of either the $C Y P 2 B 6^{*} 6 / * 6$ or $C Y P 2 B 6^{*} 1 / * 6$ genotypes. The homozygous $C Y P 2 B 6^{*} 6$ genotype was associated with $46 \%$ sensitivity and $97 \%$ specificity in predicting plasma efavirenz levels above $4 \mu \mathrm{g} / \mathrm{ml}$. The homozygous CYP2B6*6 genotype also had an $88 \%$ positive predictive value for efavirenz plasma levels above $4 \mu \mathrm{g} / \mathrm{ml}$. Therefore, given that the study found between 12.5 and $18.6 \%$ of the population to be homozygous for the *6 allele, it can be estimated that between 10 and 16\% of Bantu-speaking South African HIV/AIDS patients will have plasma efavirenz levels of above $4 \mu \mathrm{g} / \mathrm{ml}$.

The 516G $>$ T SNP has also been shown to affect nevirapine plasma concentrations. Penzak et al. (2007) reported a significant correlation between the 516G $>$ T SNP and nevirapine concentration in an HIV-positive Ugandan population. Brown et al. (2012) reported the 516G $>$ T SNP to be significantly correlated with increased nevirapine exposure in a Malawian population. However, no significant association was found between the 516G $>\mathrm{T}$ SNP and nevirapine-induced hepatotoxicity in a Mozambiquan population (Ciccacci et al., 2010). More studies involving nevirapine plasma concentrations and CYP2B6 polymorphisms are thus needed to clarify these differences in observations.

Effect of variants on immune response. When assessing the impact of polymorphisms on immune function using CD4 cell recovery as an indication of response to HAART, no significant association was found between the $516 \mathrm{G}>\mathrm{T}$ and $785 \mathrm{~A}>\mathrm{G}$ SNPs and CD4 counts in South African Xhosa and Mixed-Ancestry HIV-positive patients (Parathyras et al., 2009). Similarly, no significant correlation was found between genotype and follow up viral loads following efavirenz treatment in a South African HIV-positive population (Gounden et al., 2010). These results suggest that although these variants increase plasma concentrations of efavirenz or nevirapine leading to toxicity as previously described, immune function is unlikely to be affected. 
CYP2B6 983T>C

Allele frequencies in African populations. The 983T $>$ C SNP is the defining SNP of the $* 18$ allele, but also occurs in the *16 haplotype with the 785A>G SNP (Thorn et al., 2010). In a study investigating populations in the 1000 genomes database, the CYP2B6 983T $>C$ SNP was reported to be highly African specific, with the CYP2B $6^{*} 18$ allele having been found only in populations of African ancestry (4-12\% frequency) and in a Puerto Rican population. No other population including European Caucasian, Asian or Mexican was found to carry the CYP2B6*18 allele ( $\mathrm{Li}$ et al., 2012).

Inter-ethnic variation between African populations is evident for this SNP. In an analysis of pharmacogenetic traits in two distinct HIV-positive South African populations, the $C Y P 2 B 6^{*} 18$ variant allele was shown to occur at a frequency of $17 \%$ in a Xhosa population, and $9 \%$ in a Cape mixed ancestry population, but differed considerably when compared to the reported frequencies of 4, 7 and $2 \%$ in the Yoruba (Nigeria), Luhya (Kenya) and Maasai (Kenya) HapMap populations, respectively (Ikediobi et al., 2011). Within another Bantu-speaking South African population, the CYP2B6*18 allele was found in $5.1 \%$ of HIV-negative participants and in $12.7 \%$ of HIV/AIDS patients, with $1.7 \%$ of the HIV/AIDS patients being homozygous for this allele (Swart et al., 2013). The 983T >C SNP was reported in 4.7\% in west Africas (including Ghana, Guinea, Ivory Coast, Sierra Leone and Senegal), in 7.5\% of African-Americans and in $1.1 \%$ of Hispanic-Americans, but was not found in Papua New Guinea, Caucasian-American or Asian-American populations (Mehlotra et al., 2007). Sarfo et al. (2014) also reported a frequency of $4 \%$ in another Ghanaian population. The 983T>C SNP was reported in 9\% of an HIV-positive Zimbabwean population (Maimbo et al., 2012), and in 5-7\% of individuals in Mozambique, with no individuals being of a homozygous genotype (Ciccacci et al., 2010).

The $* 16$ haplotype $(983 \mathrm{~T}>\mathrm{C}$ and $785 \mathrm{~A}>\mathrm{G})$ is seen less frequently. Only $1 \%$ of Nigerians were found to carry the CYP2B6*16 allele, whereas this haplotype was neither seen in any other population in the 1000 genomes database, including other African, Caucasian or Asian populations (Li et al., 2012), nor it seen in a Zimbabwean population (Maimbo et al., 2012). Neither was there any indication of the *16 haplotype in West Africa and African-American populations (Mehlotra et al., 2007). However, it was reported in $6.9 \%$ of a Tanzanian population, and $4.1 \%$ in a Turkish population, where strong linkage between $983 \mathrm{~T}>\mathrm{C}$ and $785 \mathrm{~A}>\mathrm{G}$ was shown (Wang et al., 2006).

Effect of variants on efavirenz and nevirapine plasma concentration. The CYP2B6 983T $>\mathrm{C}$ SNP has been associated with increased efavirenz and nevirapine plasma concentrations and adverse side effects. When investigating nevirapine-induced hepatotoxicity, the 983T $>$ C SNP was significantly correlated with higher alanine aminotransminase (ALT) values in a Mozambique population (Ciccacci et al., 2010). Increased levels of this transaminase are associated with liver damage and hepatotoxicity. In a similar investigation using efavirenz, subjects carrying the $* 16$ allele had a three-fold higher efavirenz concentration compared to other genotypes (Wang et al., 2006). Similarly, Sarfo et al. (2014) and Elens et al. (2010) found significantly elevated efavirenz concentrations in individuals carrying the 983T $>$ C SNP. An in vitro analysis has shown the $983 \mathrm{~T}>\mathrm{C}$ variant results in decreased protein expression, with a protein level of only $15-30 \%$ of that of the wild-type CYP2B $6^{*} 1$ allele (Wang et al., 2006). Lower protein levels result in a poor metabolizer phenotype and therefore higher drug plasma concentrations leading to adverse drug reactions.

\section{CYP2B6 785A>G}

The CYP2B6 $785 \mathrm{~A}>\mathrm{G}$ variant is found alone as the CYP2B6*4 allele, but is also found as part of other haplotypes including $C Y P 2 B 6^{*} 6$ (with $516 \mathrm{G}>\mathrm{T}$ ) and $C Y P 2 B 6^{*} 16$ (with $983 \mathrm{~T}>\mathrm{C}$ ) as described previously. In the absence of other variants, the $785 \mathrm{~A}>\mathrm{G}$ SNP has been reported to be associated with higher levels of protein expression and increased enzyme activity. In an in vitro analysis, the $785 \mathrm{~A}>\mathrm{G}$ SNP alone resulted in a two-fold increase in protein expression compared to the wild-type allele (Wang et al., 2006). In combination with the 983T $>$ C SNP, the $785 \mathrm{~A}>\mathrm{G}$ SNP slightly, but not significantly, resulted in increased expression compared to constructs carrying only the 983T $>C$ SNP. The increase in expression may indicate that the $785 \mathrm{~A}>\mathrm{G}$ SNP partially overrides the inhibitory effect of the $983 \mathrm{~T}>\mathrm{C}$ SNP. The same may be true for the CYP2B6*6 allele, where the $785 \mathrm{~A}>\mathrm{G}$ SNP may partially override the inhibitory effect of the $516 \mathrm{G}>\mathrm{T}$ SNP.

\section{Other CYP2B6 haplotypes}

Differences have been reported in allele frequencies between different ethnic populations in other CYP2B6 variants. Allele frequencies differed significantly between AfricanAmericans and European-Americans for $1459 \mathrm{C}>\mathrm{T}$, which characterizes the $* 5$ allele ( 1 and $11.8 \%$, respectively, $p<0.0001$; Haas et al., 2004), indicating that the frequency of this variant may be lower in African populations. In this study, there was no significant association between the 1459C $>$ T SNP and efavirenz related central nervous system side effects. Desta et al. (2007) reported that a decrease in the CYP2B6 protein in samples with $* 1 / * 5$ and $* 5 / * 6$ genotypes, but likewise this did not result in a significant reduction in efavirenz metabolism. Within a Bantu-speaking South African population, the $1459 \mathrm{C}>\mathrm{T}$ SNP was found in $3.1 \%$ of HIV-negative participants, and in $1.4 \%$ of HIV/ AIDS patients (Swart et al., 2013). In this same population, another reduced activity polymorphism 136A $>\mathrm{G}$, which characterizes the $* 11$ allele, was found in $11.9 \%$ of HIVnegative participants and in $15.9 \%$ of HIV/AIDS patients. A total of $1.9 \%$ and $4.7 \%$ of HIV-negative and HIV/AIDS patients, respectively, were homozygous for this SNP. The *11 allele was found in $13.6 \%$ of a Ugandan population, with homozygous individuals having a 20\% lower apparent oral clearance of efavirenz (Mukonzo et al., 2009). The haplotypes $* 17, * 19, * 20$ and $* 21$ may also be considered to be African specific, as they have only been reported in populations of African origin; these haplotypes were absent in both the Asian and Caucasian populations studied (Klein et al., 2005). Other SNPs that have been associated 
with nevirapine-induced hepatotoxicity include $646-17 \mathrm{C}>\mathrm{T}$, 646-159G $>A$ and 6986A $>$ G (Ciccacci et al., 2010).

Based on the data reviewed above, there is therefore strong evidence that the $516 \mathrm{G}>\mathrm{T}$ and $983 \mathrm{~T}>\mathrm{C}$ SNPs that characterize the $* 6$ and $* 18$ haplotypes have the greatest effect on efavirenz and nevirapine plasma concentrations, and an argument can be made for decreasing dosage in individuals carrying these variants. Gatanga et al. (2007) showed that reducing the dose of efavirenz from $600 \mathrm{mg}$ to either $400 \mathrm{mg}$ or $200 \mathrm{mg}$ in individuals carrying the $* 6 / * 6$ genotype, successfully decreased efavirenz plasma concentrations and central nervous system side effects, yet successfully suppressed viral load. Such findings present an argument for the utility of pharmacogenetic testing of individuals to personalize dosage. However, due to the limited number of genotypephenotype reports in African populations, further studies are needed in these populations to determine the true correlation between the genotype of an individual and the resulting change in drug plasma levels. It will also be necessary to determine the true effect of other CYP2B6 variants on efavirenz and nevirapine plasma concentrations.

\section{CYP2A6}

Allele frequencies in African populations. CYP2A6 exhibits a high number of polymorphisms, with 45 alleles having been reported to date (http://www.cypalleles.ki.se/cyp2a6.htm [last accessed 28 October 2014]). These result in a wide range of catalytic activities, with certain variants having been shown to be of pharmacogenetic relevance. Although on the African continent CYP2A6 variants have been studied to a lesser extent than variants for CYP2B6, certain alleles have nonetheless been shown to exhibit inter-ethnic variability. Schoedel et al. (2004) reported significant ethnic variation in allele frequencies between the five ethnic groups studied (African North American, Canadian Native Indian, Caucasian, Chinese and Japanese). The *1B, *4, *7, *8 and *9 allele frequencies were significantly different between ethnic groups, with African-North Americans having lower allele frequencies $(p<0.01)$. In a study involving a Ghanaian population, the $* 1 \mathrm{~B}$ allele was observed in $11.9 \%$ of Ghanaians, while the $* 4$ whole gene deletion and the *9 decreased activity alleles were present in 1.9 and $5.7 \%$ of the Ghanaian population, respectively (Gyamfi et al., 2005).
CYP2A6 *2, *5, *6, *7, *8, *10 and *11 were not only found in the Ghanaian population, but also have been reported to be present in Asian and Caucasian populations. The $* 17$ allele is thought to be African specific, with $12 \%$ of the same Ghanaian population possessing this allele (Kwara et al., 2009a). However, the $* 17$ allele has to date not been reported in either Caucasian or Asian populations. Within a Bantuspeaking South African population, the $1093 \mathrm{G}>\mathrm{A}$ reduced activity polymorphism (present in the $* 17$ haplotype) was found in $15.6 \%$ of HIV-negative participants, and in $13.6 \%$ of HIV/AIDS patients, with $1.7 \%$ of the HIV/AIDS patients being homozygous for this SNP (Swart et al., 2013). While the *4 allele was present in the Ghanaian population (1.9\%), none of the subjects studied in a Zimbabwean population carried the whole gene deletion $C Y P 2 A 6^{*} 4$ allele (Maimbo et al., 2012). This allele has also been reported at a low frequency of $1.2 \%$ in Caucasian populations; however, it is common in Asian populations with a frequency of $24 \%$ in a Japanese population (Schoedel et al., 2004).

Effect of variants on efavirenz and nevirapine plasma concentration. Certain CYP2A6 variants have been reported to affect both efavirenz as well as nevirapine plasma concentrations. Table 2 summarizes the frequency and effect on phenotype of the CYP2A6 *9 and $* 17$ haplotypes in African populations. Di Iulio et al. (2009) reported an association between decreased and loss of function CYP2A6 alleles and efavirenz metabolite concentrations. In a Ghanaian population, the $* 9$ and/or $* 17$ alleles were significantly associated with altered efavirenz plasma concentrations, and accounted for $9 \%$ of the inter-individual variability as determined by linear regression analysis (Kwara et al., 2009b). Individuals with the $* 9$ and/or $* 17$ alleles had a $32 \%$ higher efavirenz concentration based on the regression model. Another study involving Ghanaian patients also concluded that the $-48 \mathrm{G}>\mathrm{T}$ SNP, characterizing the $* 9$ allele, was significantly associated with elevated efavirenz concentrations ( $p<0.0001$; Sarfo et al., 2014). However, the association of these SNPs with efavirenz concentration has not been reported in other studies. Of the SNPs studied by Elens et al. (2010), no significant association was seen either the $* 9 \mathrm{~b}$ or $* 17$ alleles and efavirenz concentrations. Similarly, no association was found between CYP2A6 allele frequencies

Table 2. Frequency of CYP2A6 variants and associated phenotype in populations of African origin.

\begin{tabular}{|c|c|c|c|c|c|}
\hline Population & \multicolumn{2}{|r|}{$-48 \mathrm{G}>\mathrm{T}(* 9)$} & \multicolumn{2}{|r|}{$1093 \mathrm{G}>\mathrm{A}(* 17)$} & References \\
\hline African-American & $7.1 \%$ & - & - & - & Schoedel et al. (2004) \\
\hline Zimbabwean & $7.0 \%$ & $\begin{array}{l}\text { No association with efavir- } \\
\text { enz plasma } \\
\text { concentration }\end{array}$ & $10.0 \%$ & $\begin{array}{l}\text { No significant association } \\
\text { with efavirenz plasma } \\
\text { concentration }\end{array}$ & Maimbo et al. (2012) \\
\hline
\end{tabular}

The $-48 \mathrm{G}>\mathrm{T}$ SNP characterizes the $* 9$ haplotype and the $1093 \mathrm{G}>\mathrm{A}$ SNP characterizes the $* 17$ haplotype.

"_,' indicates no data present in the published study. 
and efavirenz plasma concentrations in a Zimbabwean population (Maimbo et al., 2012). Therefore, while the $* 9$ and $* 17$ haplotypes may be variants for which a possible phenotypic effect exists, similarly to the CYP2B6 variants, further investigations are needed to clarify these relationships, particularly in African populations.

\section{UGT2B7}

Allele frequencies in African populations. The UGT2B7 enzyme is known to be polymorphic, with three nonsynonymous SNPs, as well as several synonymous, intronic and promoter SNPs (Guillemette, 2003). Four alleles (*1-*4) with sub-variants, have to date been described for UGT2B7 (http://www.pharmacogenomics.pha.ulaval.ca/files/content/ sites/pharmacogenomics/files/Nomenclature/UGT2B/UGT2 B7.htm [last accessed 28 October 2014]). When investigating worldwide variation in UGT2B7, certain significant differences were observed across different ethnic backgrounds (Li et al., 2012). The $* 2$ a allele was found to be significantly higher in European-Americans (49\%), compared to AfricanAmericans (32\%), West Africans (19\%) and individuals from Papua New Guinea (28\%). The $* 1 \mathrm{~m}$ allele was found to be significantly higher in Hispanic-Americans (37\%) than any other North American population, but was comparable to the West African population (34\%). The *3 allele was found at low frequencies in Hispanic-American and Asian-American populations, but not in any of the other populations examined. Allele *1a was highly prevalent in all populations (32-45\%), while allele $* 1 \mathrm{~b}$ had a low prevalence across all populations $(1-9 \%)$. The $* 4$ allele was not seen in any of the populations studied; however, it has previously been reported in a Japanese population (Saeki et al., 2004). Ngaimisi et al. (2013) found the frequency of the UGT2B7-327G $>$ A SNP, which occurs in certain $* 2$ alleles, to be significantly different in a Tanzanian population (29.3\%) compared to an Ethiopian population $(48.3 \%)$. The $* 1 \mathrm{c}$ and $* 2$ alleles are present in 15 and $23 \%$ of Ghanaians, respectively (Sarfo et al., 2014).

Effect of enzyme activity on efavirenz and nevirapine plasma concentration. UGT2B7 haplotypes that have been reported to have an effect on efavirenz concentration include the *1 and $* 2$ haplotypes. In a Ghanaian population, the $* 1$ a and $* 2$ alleles were significantly associated with altered efavirenz plasma concentrations, with the *1a allele accounting for $10 \%$ of the inter-individual variability seen (Kwara et al., 2009b). Individuals with the $* 1$ a allele had on average a $41 \%$ higher efavirenz plasma concentration. However, other studies have not found such an association. In another study involving Ghanaian patients, no association was found between the *1c and $* 2$ alleles and efavirenz concentration. Elens et al. (2010) as well as Bélanger et al. (2009) also concluded that the *1c and $* 2$ alleles were not associated with variations in efavirenz plasma concentrations. Likewise, no association was found between UGT2B7 allele frequencies and efavirenz plasma concentrations in a Zimbabwean population (Maimbo et al., 2012). Ngaimisi et al. (2013) also found no association between the UGT2B7-327G $>$ A SNP and efavirenz plasma concentrations. Opposing observations may be due to limited sample sizes and/or differing methodologies used and further highlight the need for additional analysis. In addition, since UGT2B7 only plays a minor role in the metabolism of efavirenz, evaluating UGT2B7 variants in conjunction with variants in CYP2B6 and CYP2A6 becomes important. The effect of UGT2B7 variants on efavirenz and nevirapine plasma concentrations in individuals with impaired CYP2B6 and/or CYP2A6 enzymes should likewise be further investigated.

Therefore, we know that the UGT2B7 enzyme plays a role in efavirenz metabolism, yet it is unclear as to what the clinical relevance of specific variants on enzyme activity might be. The $* 1 \mathrm{a}$ and $* 2$ haplotypes may represent functionally relevant alleles. It is evident that inter-ethnic differences exist in the frequency of these variants; however, the frequency of these variants in African populations is largely unknown. The number of reports detailing UGT2B7 polymorphisms in Africa and the phenotypic effect of these variants are scarce, which further highlights the need for indepth investigations in these populations.

\section{Conclusion}

Genetic polymorphisms in drug metabolizing enzymes, including CYP2B6, CYP2A6 and UGT2B7, have been shown to have potential clinical relevance with frequencies of variants exhibiting population as well as intra-population differences. In certain instances, these polymorphisms have been shown to affect plasma concentrations of the antiretroviral drugs efavirenz and nevirapine, leading to neurotoxicity and hepatotoxicity, respectively. Given the high prevalence of HIV/AIDS across Africa and in particular in sub-Saharan Africa, and the wide-spread use of both efavirenz and nevirapine in the treatment of this disease, a strong argument can be made for pharmacogenetic testing in affected populations to personalize dosage and thereby achieve optimal plasma concentrations. Pharmacogenetic research is particularly relevant in the context of the treatment of HIV on the African continent given that (a) Africans exhibit a greater degree of genetic diversity than other populations, (b) frequencies of clinically relevant polymorphisms differ between African populations and other ethnic groups and (c) the existence of African specific alleles.

There is a significant amount of evidence showing that the CYP $2 B 6^{*} 6$ and the $* 18$ alleles lead to reduced rates of efavirenz and nevirapine metabolism. As a result, individuals carrying these alleles are more prone to adverse side effects. The prevalence of $C Y P 2 B 6^{*} 6$ is higher in African populations than in Caucasians, while $* 18$ is considered to be an African specific allele. Some studies have shown that $C Y P 2 A 6^{*} 9$ and $* 17$ are associated with higher efavirenz concentrations while others have not been able to confirm these results. Given the importance of CYP2A6 in efavirenz metabolism, particularly in cases where the CYP2B6 enzyme is not fully functional, and the lack of CYP2A6 investigations in Africa, there is an urgent need for additional studies on the African continent. Ethnic differences also exist in polymorphism frequencies for the UGT2B7 enzymes; however, studies in African populations are very limited. It remains unclear whether an association between efavirenz concentrations and UGT2B7 polymorphisms exist, with the $* 1 \mathrm{a}$ and $* 2$ alleles 
demonstrating a possible association. A more extensive analysis is thus required. The relationship between concomitant variants in the CYP2B6, CYP2A6 and the UGT2B7 enzymes in the same individual and the subsequent preferred mode of metabolism may also be particularly interesting, given the critical role of accessory pathways in efavirenz metabolism in individuals with CYP2B6 reduced function alleles. A well-controlled and well-designed genotype-phenotype study of these three enzymes in African populations is therefore extremely important.

It is essential that future research must lead to a clear understanding of the correlation between genotype and phenotype in African populations, allowing appropriate conclusions to be made regarding drug dosage levels based on the presence of genetic variants. Ideally, where there is a known pharmacogenetic effect for a certain treatment, patients should be tested for the relevant polymorphisms before starting treatment, and the appropriate dose adjustment made from the outset. Pharmacogenetic research should therefore be used to inform decisions made by health authorities, with the overall aim of reducing adverse drug reactions, increasing the number of responders and improving healthcare on the African continent.

\section{Declaration of interest}

The authors have no conflicts of interest to declare. Funding was provided by the University of Pretoria Institute for Cellular and Molecular Medicine, the South African Medical Research Council and the National Research Foundation of South Africa.

\section{References}

Alessandrini M, Asfaha S, Dodgen TM, et al. (2013). Cytochrome P450 pharmacogenetics in African populations. Drug Metab Rev 45: 253-275.

Alessandrini M, Pepper MS. (2014). Priority pharmacogenetics for the African continent: Focus on CYP450. Pharmacogenomics 15: 385-400.

Bélanger AS, Caron P, Harvey M, et al. (2009). Glucuronidation of the antiretroviral drug efavirenz by UGT2B7 and an in vitro investigation of drug-drug interaction with zidovudine. Drug Metab Dispos 37: 1793-1796.

Brown KC, Hosseinipour MC, Hoskins JM, et al. (2012). Exploration of CYP450 and drug transporter genotypes and correlations with nevirapine exposure in Malawians. Pharmacogenomics 13:113-121.

Ciccacci C, Borgiani P, Ceffa S, et al. (2010). Nevirapine-induced hepatotoxicity and pharmacogenetics: A retrospective study in a population from Mozambique. Pharmacogenomics 11:23-31.

Court MH. (2010). Interindividual variability in hepatic drug glucuronidation: Studies into the role of age, sex, enzyme inducers, and genetic polymorphism using the human liver bank as a model system. Drug Metab Rev 42:209-224.

Dandara C, Swart M, Mpeta B, et al. (2014). Cytochrome P450 pharmacogenetics in African populations: Implications for public health. Expert Opin Drug Metab Toxicol 10:769-785.

De Wit E, Delport W, Rugamika CE, et al. (2010). Genome-wide analysis of the structure of the South African coloured population in the Western Cape. Hum Genet 128:145-153.

Department of Health (DOH), Republic of South Africa. (2013). The South African antriretroviral treatment guidelines. Available from: http://www.sahivsoc.org/upload/documents/2013\%20ART\%20Guide linesShort $\% 20$ Combined $\% 20$ FINAL $\% 20$ draft $\% 20$ guidelines $\% 2014 \%$ 20March\%202013.pdf [last accessed 16 Apr 2014].

Desta Z, Saussele T, Ward B, et al. (2007). Impact of CYP2B6 polymorphism on hepatic efavirenz metabolism in vitro. Pharmacogenomics 8:547-558.
Di Iulio J, Fayet A, Arab-Alameddine M, et al. (2009). In vivo analysis of efavirenz metabolism in individuals with impaired CYP2A6 function. Pharmacogenet Genomics 19:300-309.

Elens L, Vandercam B, Yombi JC, et al. (2010). Influence of host genetic factors on efavirenz plasma and intracellular pharmacokinetics in HIV-1-infected patients. Pharmacogenomics 11:1223-1234.

Gatanga H, Hayashida T, Tsuchiya K, et al. (2007). Successful efavirenz dose reduction in HIV type 1-infected individuals with cytochrome P450 2B6*6 and *26. Clin Infect Dis 45:1230-1237.

Gounden V, Van Niekerk C, Snyman T, George JA. (2010). Presence of the CYP2B6 516G $>$ T polymorphism, increased plasma Efavirenz concentrations and early neuropsychiatric side effects in South African HIV-infected patients. AIDS Res Ther 7:32.

Gross R, Aplenc R, Tenhave T, et al. (2008). Slow efavirenz metabolism genotype is common in Botswana. J Acquir Immune Defic Syndr 49: 336-337.

Guillemette, C. (2003). Pharmacogenomics of human UDP-glucuronosyltransferase enzymes. Pharmacogenomics J 3:136-158.

Gyamfi MA, Fujieda M, Kiyotani K, et al. (2005). High prevalence of cytochrome P450 2A6*1A alleles in a black African population of Ghana. Eur J Clin Pharmacol 60:855-857.

Haas DW, Bartlett JA, Andersen JW, et al. (2006). Pharmacogenetics of nevirapine-associated hepatotoxicity: An Adult AIDS Clinical Trials Group collaboration. Clin Infect Dis 43:783-786.

Haas DW, Ribaudo HJ, Kim RB, et al. (2004). Pharmacogenetics of efavirenz and central nervous system side effects: An Adult AIDS Clinical Trials Group study. AIDS 18:2391-2400.

Ikediobi O, Aouizerat B, Xiao Y, et al. (2011). Analysis of pharmacogenetic traits in two distinct South African populations. Hum Genomics 5:265-282.

Ingelman-Sundberg M, Sim SC, Gomez A, Rodriguez-Antona C. (2007). Influence of cytochrome P450 polymorphisms on drug therapies: Pharmacogenetic, pharmacoepigenetic and clinical aspects. Pharmacol Ther 116:496-526.

Ingelman-Sundberg M. (2007). Pharmacogenetics of the P450s. In: Daly A, ed. Drug metabolizing enzymes: Fundamentals, study methods, recent advances and clinical significance. The Biomedical \& Life Sciences Collection. London: Henry Stewart Talks Ltd. Available from: http://0-hstalks.com.innopac.up.ac.za/?t=BL0091124 [last accessed 28 Oct 2014].

Jamshidi Y, Moreton M, Mckeown DA, et al. (2010). Tribal ethnicity and CYP2B6 genetics in Ugandan and Zimbabwean populations in the UK: Implications for efavirenz dosing in HIV infection. J Antimicrob Chemother 65:2614-2619.

Joint United Nations Programme on HIV/AIDS. (2011). UNAIDS World AIDS Day Report 2011. UNAIDS. Available from: http://www. unaids.org/en/media/unaids/contentassets/documents/unaidspublication/2011/jc2216_worldaidsday_report_2011_en.pdf [last accessed 20 Apr 2014].

Klein K, Lang T, Saussele T, et al. (2005). Genetic variability of CYP2B6 in populations of African and Asian origin: Allele frequencies, novel functional variants, and possible implications for anti-HIV therapy with efavirenz. Pharmacogenet Genomics 15: 861-873.

Kwara A, Lartey M, Sagoe KW, et al. (2009a). CYP2B6 (c.516G->T) and CYP2A6 (*9B and/or *17) polymorphisms are independent predictors of efavirenz plasma concentrations in HIV-infected patients. Br J Clin Pharmacol 67:427-436.

Kwara A, Lartey M, Sagoe KW, et al. (2009b). CYP2B6, CYP2A6 and UGT2B7 genetic polymorphisms are predictors of efavirenz mid-dose concentration in HIV-infected patients. AIDS 23:2101-2106.

Li J, Menard V, Benish RL, et al. (2012). Worldwide variation in human drug-metabolism enzyme genes CYP2B6 and UGT2B7: Implications for HIV/AIDS treatment. Pharmacogenomics 13: 555-570.

Mahungu TW, Johnson MA, Owen A, Back DJ. (2009). The impact of pharmacogenetics on HIV therapy. Int J STD AIDS 20: $145-151$.

Maimbo M, Kiyotani K, Mushiroda T, et al. (2012). CYP2B6 genotype is a strong predictor of systemic exposure to efavirenz in HIV-infected Zimbabweans. Eur J Clin Pharmacol 68:267-271.

Mehlotra RK, Bockarie MJ, Zimmerman PA. (2007). CYP2B6 983T>C polymorphism is prevalent in West Africa but absent in Papua New Guinea: Implications for HIV/AIDS treatment. $\mathrm{Br} \mathrm{J}$ Clin Pharmacol 64:391-395. 
Michaud V, Bar-Magen T, Turgeon J, et al. (2012). The dual role of pharmacogenetics in HIV treatment: Mutations and polymorphisms regulating antiretroviral drug resistance and disposition. Pharmacol Rev 64:803-833.

Mukonzo JK, Röshammar D, Waako P, et al. (2009). A novel polymorphism in ABCB1 gene, CYP2B $6 * 6$ and sex predict singledose efavirenz population pharmacokinetics in Ugandans. Br J Clin Pharmacol 68:690-699.

Murray CJ, Vos T, Lozano R, et al. (2013). Disability-adjusted life years (DALYs) for 291 diseases and injuries in 21 regions, 1990-2010: A systematic analysis for the Global Burden of Disease Study 2010. Lancet 380:2197-2223.

Ngaimisi E, Habtewold A, Minzi O, et al. (2013). Importance of ethnicity, CYP2B6 and ABCB1 genotype for efavirenz pharmacokinetics and treatment outcomes: A parallel-group prospective cohort study in two sub-Saharan Africa populations. PLoS One 8:e67946.

Nyakutira C, Roshammar D, Chigutsa E, et al. (2008). High prevalence of the CYP2B6 516G $>\mathrm{T}(* 6)$ variant and effect on the population pharmacokinetics of efavirenz in HIV/AIDS outpatients in Zimbabwe. Eur J Clin Pharmacol 64:357-365.

Parathyras J, Gebhardt S, Hillermann-Rebello R, et al. (2009). A pharmacogenetic study of CD4 recovery in response to HIV antiretroviral therapy in two South African population groups. J Hum Genet 54:261-265.

Penzak SR, Kabuye G, Mugyenyi P, et al. (2007). Cytochrome P450 2B6 (CYP2B6) G516T influences nevirapine plasma concentrations in HIV-infected patients in Uganda. HIV Med 8:86-91.

Radloff R, Gras A, Zanger UM, et al. (2013). Novel CYP2B6 enzyme variants in a Rwandese population: Functional characterization and assessment of in silico prediction tools. Hum Mutat 34:725-734.

Riska P, Lamson M, MacGregot T, et al. (1999). Disposition and biotransformation of the antiretroviral drug nevirapine in humans. Drug Metab Dispos 27:895-901.

Saeki M, Saito Y, Jinno H, et al. (2004). Single nucleotide polymorphisms and haplotype frequencies of UGT2B4 and UGT2B7 in a Japanese population. Drug Metab Dispos 32:1048-1054.
Sarfo FS, Zhang Y, Egan D, et al. (2014). Pharmacogenetic associations with plasma efavirenz concentrations and clinical correlates in a retrospective cohort of Ghanaian HIV-infected patients. J Antimicrob Chemother 69:491-499.

Schoedel KA, Hoffmann EB, Rao Y, et al. (2004). Ethnic variation in CYP2A6 and association of genetically slow nicotine metabolism and smoking in adult Caucasians. Pharmacogenetics 14:615-626.

Swart M, Skelton M, Ren Y, et al. (2013). High predictive value of CYP2B6 SNPs for steady-state plasma efavirenz levels in South African HIV/AIDS patients. Pharmacogenet Genomics 23: 415-427.

Swart M, Skelton M, Wonkam A, et al. (2012). CYP1A2, CYP2A6, CYP2B6, CYP3A4 and CYP3A5 Polymorphisms in Two Bantu-Speaking Populations from Cameroon and South Africa: Implications for Global Pharmacogenetics. Curr Pharmacogen Pers Med 10:43-53.

Thorn CF, Lamba JK, Lamba V, et al. (2010). PharmGKB summary: very important pharmacogene information for CYP2B6. Pharmacogenet Genomics 20:520-523.

Tishkoff SA, Reed FA, Friedlaender FR, et al. (2009). The genetic structure and history of Africans and African Americans. Science 324: 1035-1044.

Wang J, Sonnerborg A, Rane A, et al. (2006). Identification of a novel specific CYP2B6 allele in Africans causing impaired metabolism of the HIV drug efavirenz. Pharmacogenet Genomics 16:191-198.

Ward BA, Gorski JC, Jones DR, et al. (2003). The cytochrome P450 2B6 (CYP2B6) is the main catalyst of efavirenz primary and secondary metabolism: Implication for HIV/AIDS therapy and utility of efavirenz as a substrate marker of CYP2B6 catalytic activity. J Pharmacol Exp Ther 306:287-300.

Warnich L, Drögemöller BI, Pepper MS, et al. (2011). Pharmacogenomic research in South Africa: Lessons learned and future opportunities in the Rainbow Nation. Curr Pharmacogenomics Person Med 9:191-207.

Whirl-Carrillo M, McDonagh EM, Herbert JM, et al. (2012). Pharmacogenomics knowledge for personalized medicine. Clin Pharmacol Ther 92:414-417. 